\title{
Effects of freezing on soil temperature, freezing front propagation and moisture redistribution in peat: laboratory investigations
}

\author{
R. M. Nagare ${ }^{1}$, R. A. Schincariol ${ }^{1}$, W. L. Quinton ${ }^{2}$, and M. Hayashi ${ }^{3}$ \\ ${ }^{1}$ Department of Earth Sciences, The University of Western Ontario, London, Canada \\ ${ }^{2}$ Cold Regions Research Centre, Wilfrid Laurier University, Waterloo, Canada \\ ${ }^{3}$ Department of Geoscience, University of Calgary, Calgary, Canada
}

Correspondence to: R. M. Nagare (rnagare@uwo.ca)

Received: 3 May 2011 - Published in Hydrol. Earth Syst. Sci. Discuss.: 31 May 2011

Revised: 16 January 2012 - Accepted: 24 January 2012 - Published: 15 February 2012

\begin{abstract}
There are not many studies that report water movement in freezing peat. Soil column studies under controlled laboratory settings can help isolate and understand the effects of different factors controlling freezing of the active layer in organic covered permafrost terrain. In this study, four peat Mesocosms were subjected to temperature gradients by bringing the Mesocosm tops in contact with subzero air temperature while maintaining a continuously frozen layer at the bottom (proxy permafrost). Soil water movement towards the freezing front (from warmer to colder regions) was inferred from soil freezing curves, liquid water content time series and from the total water content of frozen core samples collected at the end of freezing cycle. A substantial amount of water, enough to raise the upper surface of frozen saturated soil within $15 \mathrm{~cm}$ of the soil surface at the end of freezing period appeared to have moved upwards during freezing. Diffusion under moisture gradients and effects of temperature on soil matric potential, at least in the initial period, appear to drive such movement as seen from analysis of freezing curves. Freezing front (separation front between soil zones containing and free of ice) propagation is controlled by latent heat for a long time during freezing. A simple conceptual model describing freezing of an organic active layer initially resembling a variable moisture landscape is proposed based upon the results of this study. The results of this study will help in understanding, and ultimately forecasting, the hydrologic response of wetland-dominated terrain underlain by discontinuous permafrost.
\end{abstract}

\section{Introduction}

Wetland-dominated terrain underlain by discontinuous permafrost covers extensive parts of northern North America and Eurasia. The hydrologic response of these areas is poorly understood, in part due to the lack of understanding of role of individual climatological and soil related factors (e.g., initial moisture conditions) on active layer freeze-thaw processes. The active layer overlies the permafrost and undergoes seasonal freezing and thawing. In organic-covered permafrost terrain, the topography of the relatively impermeable frost table (defined as the $0^{\circ} \mathrm{C}$ isotherm) plays an important role in controlling spring runoff (Wright et al., 2009). It is broadly understood that factors such as climate, canopy cover, ground slope, and soil moisture and thermal properties of soil play critical roles in development or degradation of permafrost. The role of latent heat in the propagation of freezing front has been examined (e.g., Carey and Woo, 2005), yet the effect of different soil moisture conditions on freezing front propagation and freezing induced water redistribution remains unclear. Soil moisture profile at the onset of winter also governs the ice content in the surface layer of the organic soils. The rate of thaw propagation is affected by the initial soil ice content. Once thaw reaches a certain depth infiltration into organic soils becomes unlimited (Gray et al., 1985, 2001).

Field studies have greatly contributed in advancing the understanding of freeze-thaw processes, controls of runoff and functions of different hydrological units in organic terrains underlain by discontinuous permafrost (e.g., Quinton et 
al., 2005; Wright et al., 2009). For example, observations of Quinton and Hayashi (2008) suggest that at the onset of winter, the water table is typically deeper than $0.5 \mathrm{~m}$ below ground, while at the start of spring melt, the upper surface of the frozen, saturated soil is typically about $0.1 \mathrm{~m}$ below the ground surface. How this condition developed during the winter period remains unclear. Field investigations by Quinton and Hayashi (2008) suggest that the amount of water supplied to the soil during the spring melt event in addition to the cumulative amount of meltwater supplied during over-winter melt events, is sufficient to saturate the $\sim 0.4 \mathrm{~m}$ thick soil zone between the water table position at the time of freeze-up and the frost table position at the end of winter. However, it is not clear if water redistribution towards freezing front plays any role in development of such conditions. Subzero soil temperatures result in higher capillary pressure gradients between warmer and colder regions of frozen soils (Philip and de Vries, 1957) driving water movement towards the freezing front (Dirksen and Miller, 1966). Water carries heat and therefore alters both thermal and hydraulic properties of soil during redistribution. Water redistribution in freezing soil has been extensively studied in mineral soils in laboratory (e.g., Dirksen, 1964; Jame, 1978) and field (e.g., Kane and Stein, 1983). By comparison only a few studies have examined the process of freezing induced water movement in organic soils (e.g., Gamayunov et al., 1990; Quinton et al., 2005).

Soil column and lysimetric experiments, under controlled laboratory conditions and without external source of water, have helped comprehensively establish the process of freezing induced water redistribution in freezing mineral soils. Many examples of such experiments in frozen mineral soils can be found in literature (Dirksen, 1964; Hoekstra, 1966; Jame, 1978; Guymon et al., 1993, Stahli and Staedler, 1997; Gergely, 2007). These experiments were conducted mostly using repacked soil columns with uniform packing and cold plates at least at one column end. The other end was either thermally insulated (Mizoguchi, 1990), in contact with a warm/cold plate (Jame, 1978), or exposed in a freezer/cold room (Gergely, 2007). To best of our knowledge, study of this nature using short peat columns has been reported only by Gamayunov et al. (1990). Data from column experiments have been used to successfully verify numerical schemes and mathematical theories (e.g., Jame and Norum, 1980; Hansson et al., 2004). However, Zhang et al. (2010) point to limitations of numerical schemes verified with such data when applied to non-uniform/ layered soil conditions, or large flux conditions such as snow melt infiltration. Data for such verification cases is scarce and therefore experiments under controlled laboratory settings need to be aimed at observing freeze-thaw processes that emulate field conditions as closely as possible (e.g., undisturbed soil cores) with realistic boundary conditions.

Field studies in the recent years have helped us understand the role of peat plateaus (permafrost slopes), elevated above the bog levels, in routing of runoff (e.g., Woo, 1986). The lateral flow rates decrease in these organic covered terrains as the frost table depths increase (Glenn and Woo, 1987) due to large reduction of saturated hydraulic conductivity of peat with depth (Quinton et al., 2000). The frost table position and topography therefore plays an important role as it defines the hydrologic function of permafrost slopes. Frost table surveys have shown that there is a strong relationship between soil moisture and frost table position and topography (Wright et al., 2009). However, it has not yet been established comprehensively if water migration towards the freezing front plays any role in setting up of the frost table. This partly because it is difficult to establish the role of water movement based on field studies alone due to uncertainties in deciding the origin of water participating in active layer freeze-up (e.g., inter-winter snowmelt vs. water migration). This study uses four Mesocoms that are thermally insulated on the sides and contain a basal layer of peat that is continuously frozen to simulate permafrost (proxy permafrost). The air above the Mesocosms was maintained at temperatures below $0{ }^{\circ} \mathrm{C}$ so that the unfrozen peat above the simulated permafrost could be subjected to bidirectional, one-dimensional freezing. Although the experimental design is similar to past column experiments in regards to subjecting the columns to a thermal gradient by maintaining temperature at ends, having a proxy permafrost allows for a clear transition zone as is present in the field. The influence of initial soil moisture on freezing processes was studied by maintaining the four Mesocosms at different water contents at the start of freezing.

The experiments are aimed at complementing the understanding generated from the field investigations in organic covered discontinuous permafrost terrain (e.g., Quinton et al., 2005; Wright et al., 2009). In particular the process of water redistribution in freezing peat has not been studied in the past and needs to be investigated in isolation to support the long term field studies. Study of water redistribution in freezing peat is the major focus of this paper along with other objectives as described below. The experiments were specifically aimed at:

1. Observing the process of freezing-induced water redistribution in peat, and the role of the initial soil water content in movement of water towards the freezing fronts. Correlating the freezing-induced soil water redistribution to the over-winter moisture redistribution observed in the field is needed to understand the overwinter moisture redistribution processes that result in the saturation of most of the active layer by the end of winter.

2. Understanding if the initial soil moisture profile governs the ice content in the peat near the ground surface, which has implications for the partitioning of snowmelt water into infiltration and runoff. 
3. Understanding the effects of initial water content on (a) soil freezing characteristics; and (b) soil thermal properties and freezing front propagation.

4. Organizing the observations of this study into a simple conceptual model to describe the processes of freezing front movement and freezing induced water redistribution.

\section{Methodology}

\subsection{Experimental setup}

The experimental setup consisted of four peat Mesocosms (M1, M2, M3 and M4), each $\sim 110 \mathrm{~cm}$ deep and $56 \mathrm{~cm}$ in diameter. All Mesocosms consisted of a $\sim 45 \mathrm{~cm}$ thick proxy permafrost layer prepared by packing unprocessed humified peat to a bulk density of $\sim 250 \mathrm{~kg} \mathrm{~m}^{-3}$. Once prepared, this layer was completely saturated and allowed to freeze at $-6^{\circ} \mathrm{C}$. Intermediate layers of unprocessed humified peat were then packed in each Mesocosm (bulk density varying from $\sim 250 \mathrm{~kg} \mathrm{~m}^{-3}$ to $\sim 125 \mathrm{~kg} \mathrm{~m}^{-3}$ ) to a thickness that allowed $\sim 110 \mathrm{~cm}$ deep Mesocosms to be formed when the undisturbed field sampled cores were placed over these layers (Table 1). In field peat can have bulk densities $\left(\rho_{\mathrm{b}}\right)$ as low as $35 \mathrm{~kg} \mathrm{~m}^{-3}$ and porosities sometimes exceeding $96 \%$ by volume. These characteristics are common in the peat deposits at or near the ground surface (e.g., Schlotzhauer and Price, 1999; Quinton et al., 2009) and difficult to replicate along with the structure by packing. The high porosities and peat structure result in significant changes in the thermal and hydrological properties of peat as soil water content varies (de Vries, 1963; Smerdon and Mendoza, 2010). The unprocessed humified peat used for proxy permafrost and intermediate layers was obtained from the Upsala, Ontario operations of Peat Resources Ltd. The undisturbed cores were extracted from Scotty Creek watershed, Northwest Territories, Canada situated in the wetland-dominated, discontinuous permafrost region. Details of the site location, landform types and site characteristics can be found in Quinton et al. (2008), and details of coring methodology can be found in Nagare (2011). Dry bulk densities and porosities for Scotty Creek peat as reported by Hayashi et al. (2007) are shown in Fig. 1a and b. The vertical hydraulic conductivity of saturated peat was measured for different depths in the laboratory (Fig. 1c). Water retention characteristics for the peat layers were reported by Quinton and Hayashi (2005) as shown in Fig. 1d. In general, deeper peat layers hold more water at higher tension. The water pressure head-unsaturated hydraulic conductivity relationship as used by Zhang et al. (2010) in their study of infiltration into frozen peat at Scotty Creek site is shown in Fig. 2. For a comparison, the water content-water pressure head relationship for upper and lower peat layers as reported by Zhang et al. (2010) are also shown in Fig. 1d using blue and red
Table 1. Details of the thickness $(\mathrm{cm})$ of peat layers in each Mesocosm.

\begin{tabular}{cccc}
\hline Mesocosm & $\begin{array}{c}\text { Undisturbed } \\
\text { peat (top } \\
\text { of core) }\end{array}$ & $\begin{array}{c}\text { Repacked } \\
\text { layer (middle } \\
\text { of core) }\end{array}$ & $\begin{array}{c}\text { Repacked } \\
\text { frozen } \\
\text { layer } \\
\text { (bottom of } \\
\text { the core) }\end{array}$ \\
\hline M1 & 42 & 18 & 45 \\
M2 & 50 & 15 & 45 \\
M3 & 17 & 51 & 45 \\
M4 & 57 & 8 & 45 \\
\hline
\end{tabular}

lines respectively. The samples did not contain any mineral material, and their ash content was $<2 \%$ of dry weight. For peat from the same site, Rezanezhad et al. (2009) found the degree of humification on the von Post scale to change from $\mathrm{H} 3$ just below surface vegetation to $\mathrm{H} 5$ at a depth of $65 \mathrm{~cm}$.

The Mesocosms were setup in the Earth Science module (BESM) of the Biotron Institute for Experimental Climate Change at the University of Western Ontario. The BESM is a two level biome with four dedicated compressors, two each for the upper and lower chambers with an air temperature control range of $-40^{\circ} \mathrm{C}$ to $+40^{\circ} \mathrm{C}$. By situating the Mesocosms between these two chambers it was possible to maintain a frozen state in the lower $\sim 45 \mathrm{~cm}$ of the core while allowing for freezing and thawing of the overlying peat. Light intensity, rain, relative humidity, wind speeds, and $\mathrm{CO}_{2}$ concentrations can be controlled independently in upper chamber. Further details on the BESM facility can be found in Nagare (2011).

Mesocosms were instrumented at different depths with time domain reflectometry (TDR) sensors (TDR100, CS610 and CS635 probes, Campbell Scientific, Inc., Logan UT) and temperature sensors (107BAM, Campbell Scientific, Inc., Logan UT). A heat flux plate each (HFT3, Campbell Scientific, Inc., Logan UT) was inserted near the soil's surface in M2 and M3. The depths at which sensors were places are given in Table 2. The Mesocosms were placed on four $81 \mathrm{~cm} \times 81 \mathrm{~cm}$ load cells (KC600S, $10 \mathrm{~g}$ precision over $600 \mathrm{~kg}$, Mettler Toledo Canada, Mississauga, ON) for continuous weighing such that the bottom $\sim 45 \mathrm{~cm}$ of the Mesocosms were the in lower chamber and the remainder protruded into the upper chamber. The sides of the Mesocosms were insulated using a combination of neoprene foam and mineral fibre insulation. The lower chamber was maintained at $-1.9^{\circ} \mathrm{C}$ to keep the bottom $\sim 45 \mathrm{~cm}$ of the cores continuously frozen while the air temperature was varied in the upper chamber. Figure 3 shows a schematic of the experimental setup with detailed explanation of various components. Soil dielectric permittivity, temperature, heat flux and weight were recorded every $15 \mathrm{~min}$. 
Table 2. TDR and temperature (Temp.) probe locations below surface (cm) in each Mesocosm. In addition to these probes, heat flux plates were inserted at $8 \mathrm{~cm}$ in Mesocosms 2 and 3.

\begin{tabular}{|c|c|c|c|c|c|c|c|}
\hline \multicolumn{2}{|c|}{ Mesocosm 1} & \multicolumn{2}{|c|}{ Mesocosm 2} & \multicolumn{2}{|c|}{ Mesocosm 3} & \multicolumn{2}{|c|}{ Mesocosm 4} \\
\hline TDR & Temp. & TDR & Temp. & TDR & Temp. & TDR & Temp. \\
\hline $\begin{array}{l}5,10 \\
15,25 \\
37,52\end{array}$ & $\begin{array}{l}0,5,10 \\
15,25 \\
37,52 \\
64,72\end{array}$ & $\begin{array}{l}3,8,13, \\
18,28, \\
40,55\end{array}$ & $\begin{array}{l}0,3,8 \\
13,18 \\
28,40 \\
55,72.5 \\
84\end{array}$ & $\begin{array}{l}5,10,15 \\
20,30 \\
42,57\end{array}$ & $\begin{array}{l}0,3,8, \\
13,18, \\
25,37, \\
47,60, \\
80\end{array}$ & $\begin{array}{l}5,10 \\
15,25 \\
37,52\end{array}$ & $\begin{array}{l}0,5,10 \\
15,25 \\
37,52 \\
64,72\end{array}$ \\
\hline
\end{tabular}
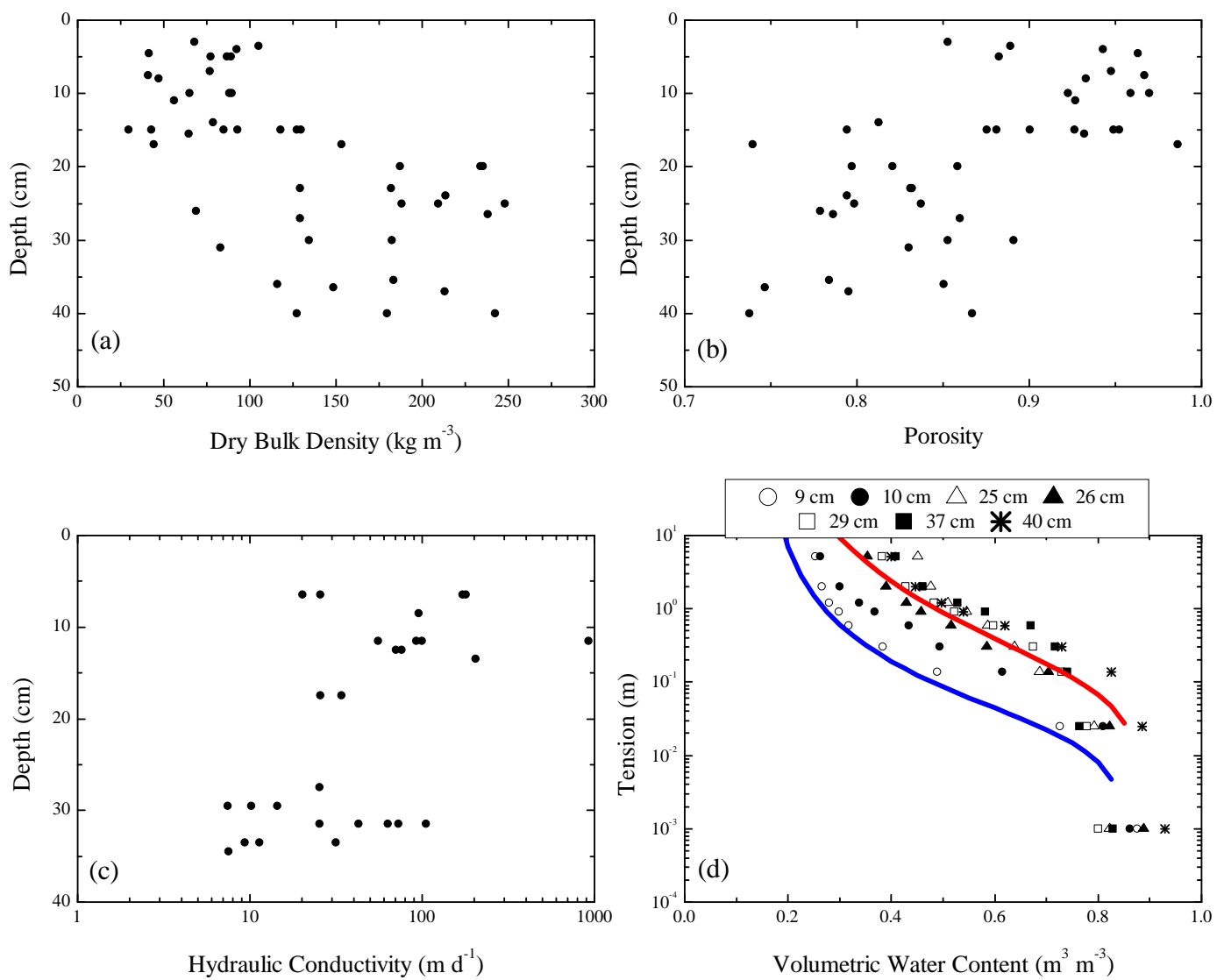

Fig. 1. Depth variation of (a) Bulk density (Hayashi et al., 2007), (b) porosity (Hayashi et al., 2007), (c) vertical hydraulic conductivity, and (d) soil water retention curves (Quinton and Hayashi, 2005) for peat from Scotty Creek watershed. The different symbols in (d) represent the samples taken at different depths as shown in legend. Also shown in (d) are the van-Genuchten models for upper peat layers (blue line) and lower peat layers (red line) as reported by Zhang et al. (2010) during numerical study of infiltration in frozen peat at Scotty Creek.

\subsection{Experimental conditions}

Two freezing runs were conducted. In the first run, the Mesocosms were subjected to air temperature in the upper chamber of $-5^{\circ} \mathrm{C}$ for 31 days and then $-10^{\circ} \mathrm{C}$ in the following 16 days. This first run was aimed at understanding the freezing characteristics in general. All four Mesocosms had an unfrozen, saturated layer at the commencement of the first freezing run with water table depths of 27-, 43-, 40- and $32 \mathrm{~cm}$ below the surface respectively. To establish saturated layers within the Mesocosms, water was sprayed daily (twice a day in different amounts) on the surface and the Mesocosms were allowed to equilibrate for at least 30 days. After 47 days of freezing, it took 75 days to thaw the active layer down to the top of the proxy permafrost layer. The air temperature in the upper chamber was maintained constant 


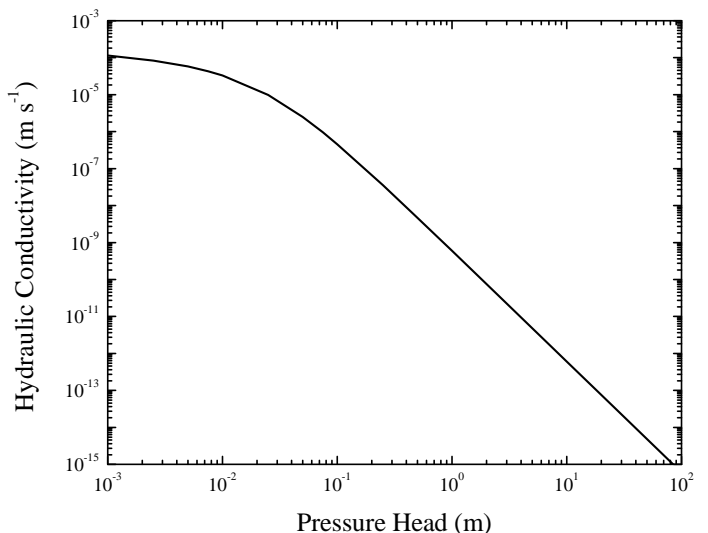

Fig. 2. Unsaturated hydraulic conductivity-water pressure head model (based on van-Genuchten equation) reported by Zhang et al. (2010) during numerical study of infiltration in frozen peat at Scotty Creek. The model has not been validated for unsaturated hydraulic conductivity values from Scotty Creek, but was developed based on values from another field site and validated numerically. Reduction in hydraulic conductivity due to ice formation is not included.

at $15^{\circ} \mathrm{C}$ and lights (wavelength: $400-750 \mathrm{~nm}$ ) were kept on such that the soil surface level received an energy input of $160 \mathrm{~W} \mathrm{~m}^{-2}$. A further 75 days were required to establish the initial conditions for the second freezing run. The air temperature in the upper chamber was maintained at $-7.5^{\circ} \mathrm{C}$ for 93 days during the second freezing run. The air temperature in the lower chamber was kept constant at $-1.9^{\circ} \mathrm{C}$. Most of the data from first freezing run could not be used because of sequential failure of temperature sensors during this run. Therefore, soil freezing characteristics and influence of initial water content on soil water redistribution and freezing front propagation was examined from the data of the second freezing run. Three additional temperature sensors at depths of 8-, 28- and $55 \mathrm{~cm}$ were inserted in peat near the wall of container holding Mesocosm 2. This was done in order to determine the performance of the experimental setup by comparing with the temperature readings of the central sensors (Fig. 4). A complete evaluation of the experimental setup with regards to its performance is given in Nagare (2011).

\subsection{TDR calibration}

A detailed calibration of the TDR100 was performed by Nagare et al. (2011) at a constant temperature $\left(30^{\circ} \mathrm{C}\right)$ using undisturbed peat samples from the Scotty Creek field site. The temperature effects on relative bulk dielectric permittivity of soil $(\varepsilon)$ have been studied in the past (e.g., Pepin et al., 1995). In freezing soils it has been shown that the temperature effects are primarily due to the temperature- $\varepsilon$ relationship of water (e.g., Watanabe and Wake, 2009). Maxwell De-Loor's (MDL) mixing model can efficiently handle the temperature effects on the $\varepsilon$-volumetric water content $(\theta)$

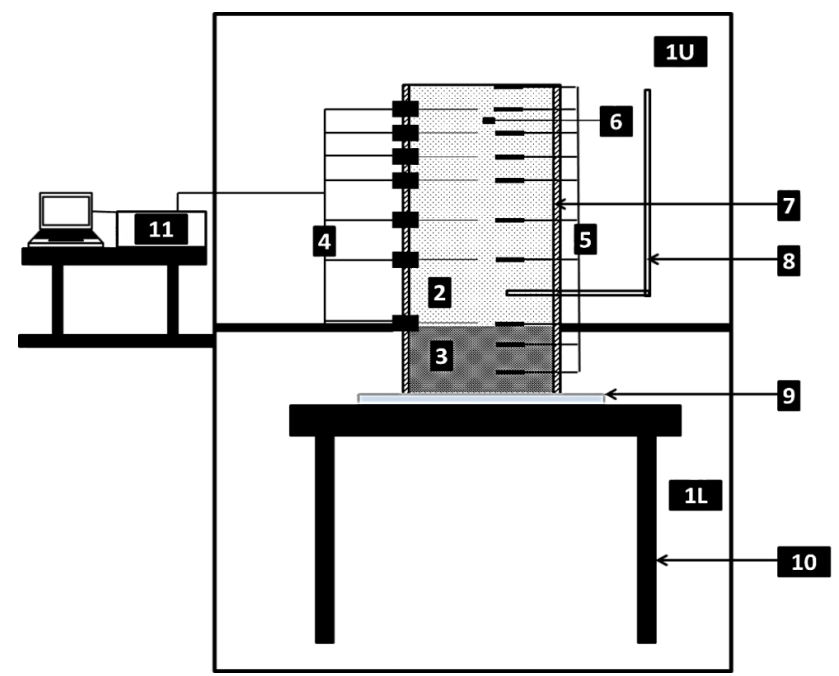

Fig. 3. Line diagram showing the experimental setup. U: upper level chamber of the BESM; 1L: lower level chamber of the BESM; 2: 65-75 cm deep unfrozen layer; $3: 45 \mathrm{~cm}$ bottom frozen layer (fully saturated before freezing); 4: TDR probes connected to 11 through low-loss coaxial cables; 5: temperature probes connected to 11 ; 6 : heat flux plate; 7: LDPE container lined with neoprene from inside and insulated from outside; 8: stand pipe for water level measurements; 9: weighing scale; 10: custom made stand to support the entire experimental setup; 11: multiplexers and datalogger connected to a personal computer.
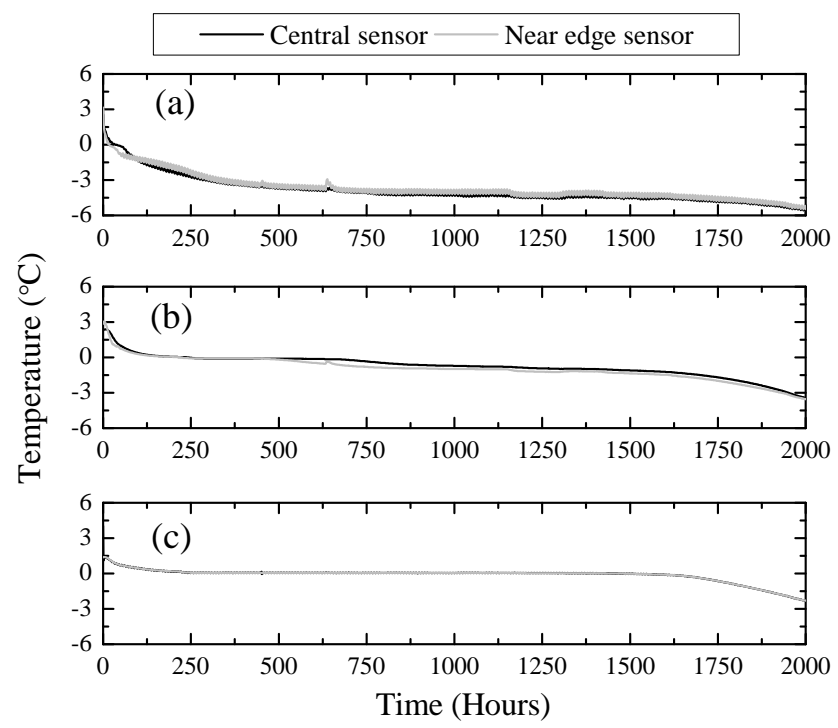

Fig. 4. Comparison between temperature time series of near-edge and central sensors located at (a) $8 \mathrm{~cm}$, (b) $28 \mathrm{~cm}$ and (c) $55 \mathrm{~cm}$ below peat surface.

relationship. Therefore, MDL model was used to estimate water content from observed $\varepsilon$ after calibrating with the empirical equation given by Nagare et al. (2011). Although the unfrozen water content can be overestimated by as much as $7 \%$ when ice contents exceed $60 \%$ by volume, the effect of 
ice on $\varepsilon$ could not be incorporated because of inability of determining ice contents at different time points in our experiments. The MDL mixing model equation is given as:

$\theta=\frac{3\left(\varepsilon_{\mathrm{s}}-\varepsilon\right)+\theta_{\mathrm{bw}}\left(2\left(\varepsilon_{\mathrm{bw}}-\varepsilon_{\mathrm{fw}}(T)\right)-\varepsilon \varepsilon_{\mathrm{s}}\left(\frac{1}{\varepsilon_{\mathrm{bw}}}-\frac{1}{\varepsilon_{\mathrm{fw}}(T)}\right)\right)+\eta\left(2\left(\varepsilon_{\mathrm{a}}-\varepsilon_{\mathrm{s}}\right)-\varepsilon \varepsilon_{\mathrm{s}}\left(\frac{1}{\varepsilon_{\mathrm{a}}}-\frac{1}{\varepsilon_{\mathrm{s}}}\right)\right)}{\varepsilon \varepsilon_{\mathrm{s}}\left(\frac{1}{\varepsilon_{\mathrm{fw}}(T)}-\frac{1}{\varepsilon_{\mathrm{a}}}\right)+2\left(\varepsilon_{\mathrm{a}}-\varepsilon_{\mathrm{fw}}(T)\right)}$

where subscripts s, bw, fw and a represent soil solids, bound water, free water and air respectively, $\eta$ is total porosity and $T$ is the soil temperature $\left({ }^{\circ} \mathrm{C}\right)$. Bound water was ignored as it was found to have very little influence given its small quantities as shown by Nagare et al. (2011). The temperature dependency of $\varepsilon_{\mathrm{fw}}$ was incorporated in the MDL model using the relationship given by Wohlfarth (2010):

$\varepsilon_{\mathrm{fw}}(T)=\left\{\begin{array}{ll}249.21-0.79(T+273.15)+0.00073(T+73.15)^{2} & 0 \leq T \leq 99 \\ 88 & T \leq 0\end{array}\right.$.

\subsection{Final total water content}

Final total water content (ice + liquid water) was measured at the end of the second freezing run for all four Mesocosms. Cores were extracted from the frozen Mesocosms using a custom designed coring tool $(30 \mathrm{~cm}$ long thin walled stainless steel tube; $2.03 \mathrm{~cm}$ inner diameter) powered by an electric drill. Two cores each from M2 and M4 were sampled from depth intervals $0-25 \mathrm{~cm}$ and $\sim 25-45 \mathrm{~cm}$ by slowly drilling into the samples in two depth increments. Two cores between depth intervals $0-25 \mathrm{~cm}$ and $\sim 25-36 \mathrm{~cm}$ could be extracted from M1. The final water content in M3 could be determined only for the upper $9.1 \mathrm{~cm}$, as efforts to core deeper in this Mesocosm did not succeed due to high ice contents. The cores were cut while frozen into smaller sections, weighed and oven dried at $87^{\circ} \mathrm{C}$ until no further change in weight was recorded. The dry samples were weighed again for gravimetric measurement of the final total water content.

The cores were extracted near the edges of the Mesocosms. Although it is best to determine total water content at different depths for entire soil column, it was not possible in our case as we continued using the Mesocosms for further research on freezing and thawing processes in peat. Extracting cores near edge may have resulted in relatively unrealistic final total water contents possibly because of different flow regimes near column edges, lateral heat leak effects and lateral redistribution of water within the Mesocosms. However, in this study the data from the cores is assumed to be good enough for the purpose of process based discussion.

\section{Results and discussion}

\subsection{Initial conditions}

The influence of water content at the start of the freezing run on active layer freezing processes was studied during the second freezing run. Initial water content is the unfrozen water content at the start of the freezing run estimated from
TDR observations. Mesocosms 1 and 4 were variably saturated at the start of this freezing run with the water tables located at $42 \mathrm{~cm}$ and $27 \mathrm{~cm}$ below the ground surface respectively. Mesocosm 2 was variably saturated throughout the depth with no saturated zone, while the water table was located at $\sim 5.5 \mathrm{~cm}$ in Mesocosm 3 at the start of the freezing run. The initial temperature profile in each Mesocosm was achieved by maintaining the air temperatures in lower and upper chambers at $-1.9^{\circ} \mathrm{C}$ and $4{ }^{\circ} \mathrm{C}$ respectively until a relatively stable profile was achieved. Figure 5 shows the initial water content and temperature profiles in all four Mesocosms at the start of the second freezing run.

\subsection{Soil freezing characteristics}

Soil freezing characteristics (SFCs) at different depths were determined from observed liquid water content and soil temperature data collected during the second freezing run. Water in $\mathrm{M} 1, \mathrm{M} 2, \mathrm{M} 3$ and $\mathrm{M} 4$ started to freeze at $-0.08^{\circ} \mathrm{C}, 0^{\circ} \mathrm{C}$, $-0.05^{\circ} \mathrm{C}$ and $-0.08^{\circ} \mathrm{C}$ respectively, and represent the temperatures at which peat water starts to freeze (freezing point before further depression) in each Mesocosm in the discussion to follow (Fig. 6). It is evident that some water remained unfrozen even after $2000 \mathrm{~h}$ ( 83 days) of freezing with residual liquid water contents between $0.02 \mathrm{~m}^{3} \mathrm{~m}^{-3}$ and $0.11 \mathrm{~m}^{3} \mathrm{~m}^{-3}$ continuing to exist even at $-5^{\circ} \mathrm{C}$. Depths with higher initial water contents are left with slightly larger amounts of residual water at similar temperatures, which could be because of influence of pore size distribution as well as varying ice content on TDR readings. Overall the SFCs appear to follow a common path during freezing. As theorized by Low et al. (1968), liquid water content in frozen soils must have a fixed value for each temperature at which the liquid and ice phase are in equilibrium, regardless of the amount of ice present. It is convenient to define a single soil freezing curve for a particular soil type in order to simplify the relationship between soil temperature and liquid water content. An example of a single curve defining the temperature-liquid water content relationship based on the van Genuchten model (van Genuchten, 1980) is shown in Fig. 7. The curve was obtained by fitting into the soil temperature and liquid water content data. This approximation of the SFCs in a single curve is important for numerical studies as it simplifies the constitutive relationship between soil temperature and liquid water content.

\subsection{Freezing induced water redistribution within the active layer}

Soil water redistribution during the second freezing run in each Mesocosm was inferred based on initial and final total water contents, liquid water content time series (Fig. 8) and SFCs at different depths. 


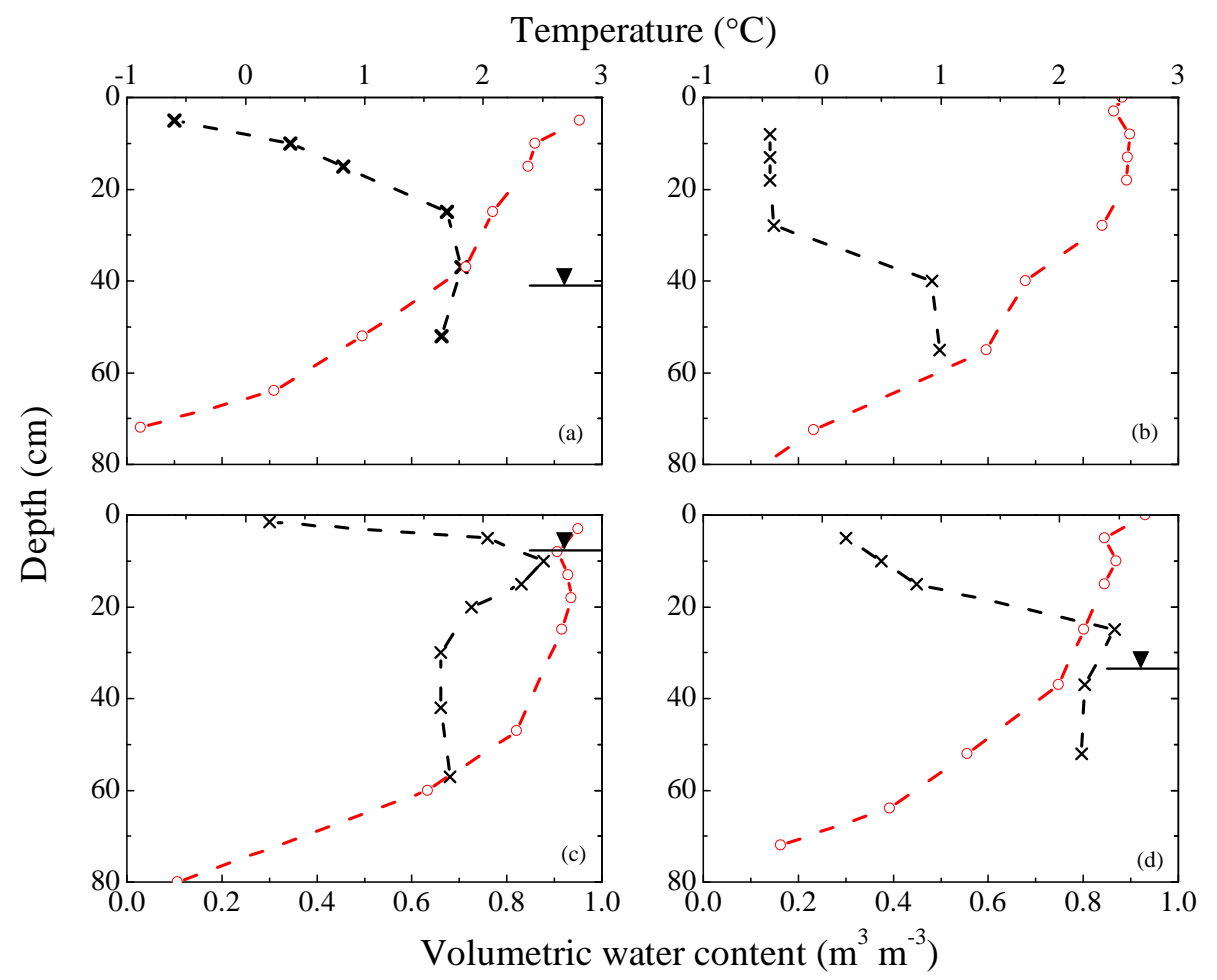

Fig. 5. Initial temperature (red line) and water content (black line) in Mesocosms (a) 1, (b) 2, (c) 3, and (d) 4 for second freezing run. The depth to the groundwater table is shown by free water surface symbol. Mesocosm \# 2 was unsaturated throughout the depth for before the second freezing run.

\subsubsection{Variably saturated conditions with a water table at depth (Mesocosms 1 and 4)}

In both M1 and M4 water from the zone near and above the water table is redistributed most likely towards the freezing front before the soil temperature falls below the freezing point. This movement is evident from the reduction of water content at $15 \mathrm{~cm}$ and $25 \mathrm{~cm}$ depths prior to soil freezing (Fig. 6a and d). Combining these SFC's with final total water contents in Mesocosms 1 and 4 (Fig. 10a and d), it can be presumed that the water moved upwards toward the downward propagating freezing front. Freezing reduces the soil pore pressures significantly because soil retains unfrozen water (Dash et al., 1995) creating large pore pressure gradients between the colder and warmer regions. A reduction in water content can be observed at different depths in both M1 and M4 prior to the temperature falling to freezing point. For example, before the arrival of freezing front the reduction in water content of $\sim 0.07 \mathrm{~m}^{3} \mathrm{~m}^{-3}$ at $25 \mathrm{~cm}$ depth in M1 $(237 \mathrm{~h})$ and $\sim 0.27 \mathrm{~m}^{3} \mathrm{~m}^{-3}$ in M4 (281 h) can be observed. A simple calculation using hydraulic conductivities from Fig. 2 indicates that potential gradients of $\sim 4 \mathrm{~m} \mathrm{~m}^{-1}$ in M1 and $\sim 0.12 \mathrm{~m} \mathrm{~m}^{-1}$ in M4 are required to cause such magnitudes of water flow towards the freezing front. Note that the model presented in Fig. 2 does not include reduction in hydraulic conductivity due to ice formation and was used by Zhang et al. (2010) for numerical study of infiltration process in frozen peat at Scotty Creek field site. The existing potential gradients even before the effects of freezing on pore pressure as inferred from Figs. 1d and 5 are much larger ( $\sim 18 \mathrm{~m} \mathrm{~m}^{-1}$ in M1 and $\sim 7 \mathrm{~m} \mathrm{~m}^{-1}$ in M4). If the effect of ice formation on hydraulic conductivities is considered, the difference in amount of water movement could be explained by the hydraulic conductivity differences resulting from water content differences in the upper $10 \mathrm{~cm}$ of these two Mesocosms. Gamayunov et al. (1990) give detailed explanation of moisture migration mechanisms towards freezing front in freezing peat. Their experiments comprehensively show a slow but large amount of water movement towards freezing front. Quinton et al. (2009) show prominent existence of connected water films (flow networks) even at reduced hydraulic conductivities in peat. The process of moisture migration in peat is more diverse than in mineral soils and differences include the easily deforming nature of peat particles which further aids moisture migration (Gamayunov et al., 1990). The final total water contents in Mesocosms 1 and 4 (Fig. 10a and d) also indicate differences in water movement and the location of maximum water accumulation in these two Mesocosms. This appears to be partly attributed to the differences in hydraulic conductivities $\left(\sim 10^{-12}\right.$ vs. $\left.\sim 10^{-8} \mathrm{~m} \mathrm{~s}^{-1}\right)$ in the upper $10 \mathrm{~cm}$ of these two Mesocosms. In addition, based on 

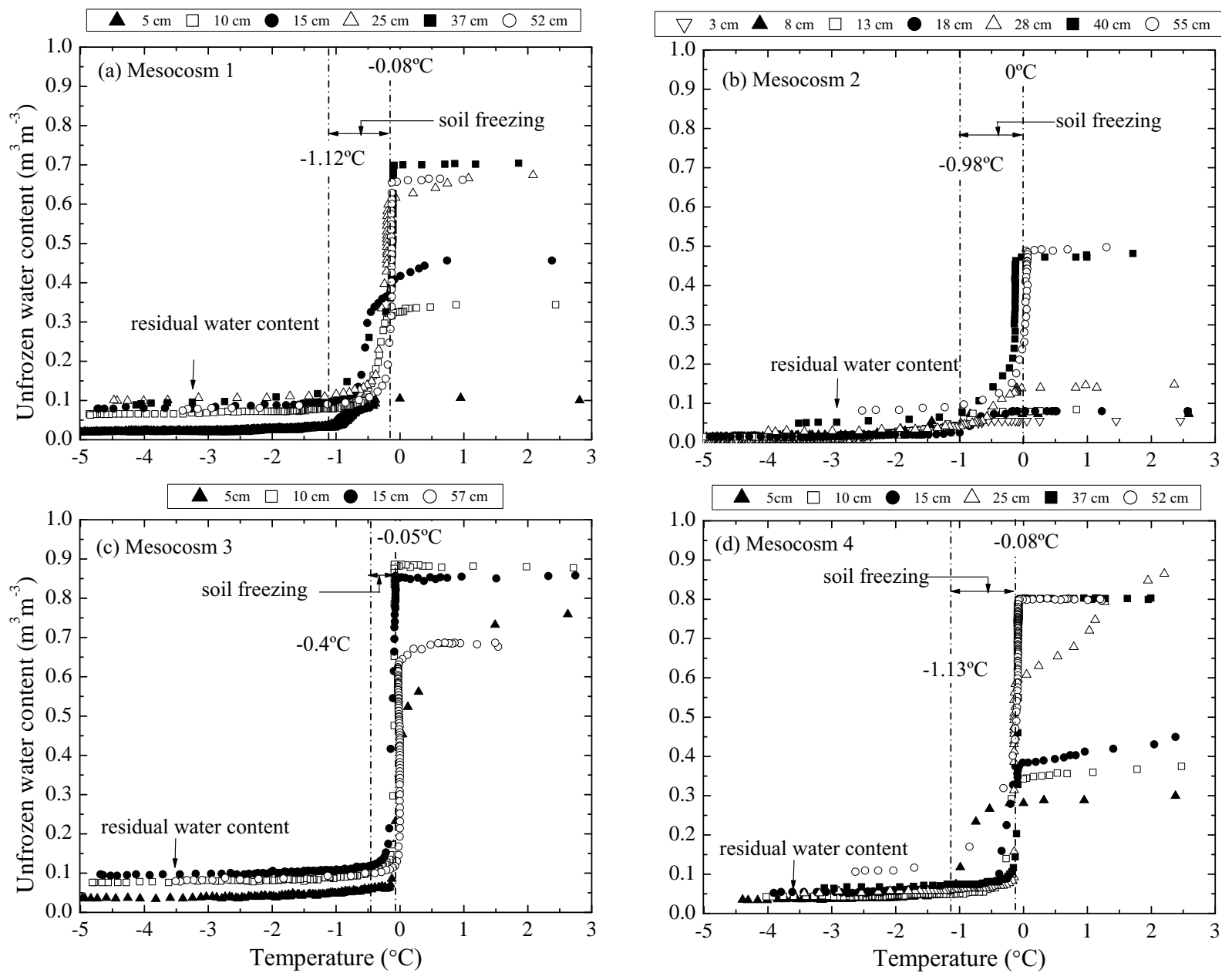

Fig. 6. Soil freezing characteristics of all four Mesocosms obtained from recorded unfrozen water and soil temperature data.

the mechanism explained by Gamayunov et al. (1990), dry initial conditions in upper $10 \mathrm{~cm}$ of Mesocosm 1 must have resulted in very less compression of the peat particles necessary for water migration into this zone.

\subsubsection{Dry conditions (Mesocosm 2)}

Mesocosm 2 was the driest among the four at the start of second freezing run with only residual water contents in upper $30 \mathrm{~cm}\left(\sim 0.15 \mathrm{~m}^{3} \mathrm{~m}^{-3}\right.$ at $28 \mathrm{~cm}$, Fig. $\left.5 \mathrm{~b}\right)$, had no saturated layer and had a degree of saturation of $\sim 50 \%$ at $55 \mathrm{~cm}$. No reduction of water content was observed in M2 at temperatures above freezing (Fig. 6b). This can be attributed to extremely low hydraulic conductivities $\left(10^{-12} \mathrm{~m} \mathrm{~s}^{-1}\right)$ in the dry zone. In addition, as explained by Gamayunov et al. (1990), water migration in freezing peat only takes place at higher moisture contents because of its complex mechanisms involving the deformation of the peat material. This is corroborated well by the final total water content profile for Mesocosm 2 (Fig. 10b).

\subsubsection{Saturated conditions (Mesocosm 3)}

At the start of the freezing run, the water table in M3 was at $\sim 5.5 \mathrm{~cm}$. It is difficult to infer any water movement for this Mesocosm from SFC alone, except at $5 \mathrm{~cm}$ depth, where water loss commenced prior to the temperature falling below freezing.

Water movement in freezing peat, as explained by Gamayunov et al. (1990), is driven by water concentration gradients and steep water content gradients at the start of freezing could have aided in water movement in M1 and M2. The weights of the Mesocosms 1 and 2 continued to drop during the entire freezing period and resulted into weight changes of $\sim 5 \mathrm{~kg}$ (M1) and $\sim 4.5 \mathrm{~kg}$ (M2). This indicates that water was escaping from the Mesocosms during freezing (evaporation or sublimation). The total amount of water equivalent to $\sim 18.56 \mathrm{~mm}$ and $\sim 16.7 \mathrm{~mm}$ respectively escaped from these two Mesocosms. 


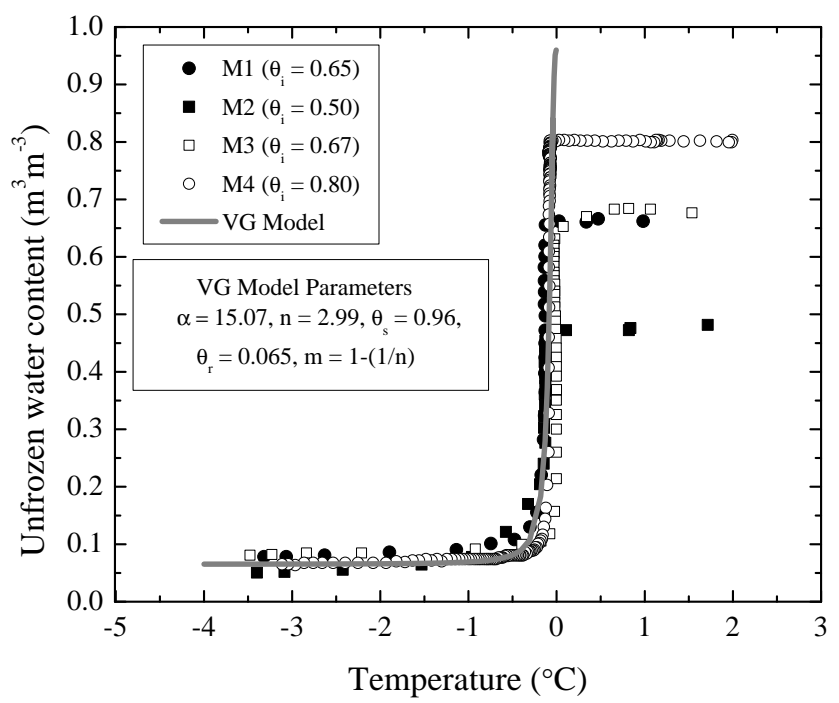

Fig. 7. Soil freezing curves chosen from four different Mesocosms and initially at different water contents $\left(\theta_{i}\right)$. A best fit defined by van-Genuchten model (VG Model, van Genuchten, 1980) is also shown along with the VG Model parameters. The SFC's were chosen from each Mesocosm such that $\theta_{i} \geq 0.5 \mathrm{~m}^{3} \mathrm{~m}^{-3}$.

\subsection{Significance for field studies}

One critical issue in field studies is to understand the role of over-winter snowmelt events, and the origin of water participating in the freezing of active layer over the winter season. Figure 11 shows the water content values observed at the Scotty Creek research site at beginning and end of winter season of 2002-2003. Initial moisture conditions for the field were not measured below $40 \mathrm{~cm}$. The depth to permafrost at the onset of winter was $70 \mathrm{~cm}$. This site is underlain by sporadic/discontinuous permafrost (Smith et al., 2004; Quinton and Hayashi, 2005).

Figure 11 indicates that water from other zones may have moved into $0-40 \mathrm{~cm}$ depths during winter. Comparing Figs. 10 and 11 indicates that it is possible that water from deeper zones at initial high water contents moved upward towards the freezing front during the winter season and resulted into the final profiles in Fig. 11. The measurements in Fig. 11 indicate $41.85 \mathrm{~mm}$ change (average of two cores) in storage in the upper $40 \mathrm{~cm}$ depth. A change of storage of $33.65 \mathrm{~mm}$ and $42.11 \mathrm{~mm}$ in upper $29 \mathrm{~cm}$ and $21 \mathrm{~cm}$ in M1 and M4 respectively was inferred from the initial and final profiles (Fig. 10). Mass balance calculation for Mesocosm 4 indicates that this increase in storage is $17 \mathrm{~mm}$ higher than explained by the loss from the deeper depths. As explained in Sect. 2.4, the frozen cores were taken near the edges of the Mesocosms and thus there could have been variable movement as well as lateral redistribution. Additionally, the cores were not taken for the entire column depths and not accounting the loss of water from depth $>45 \mathrm{~cm}$ could in part explain

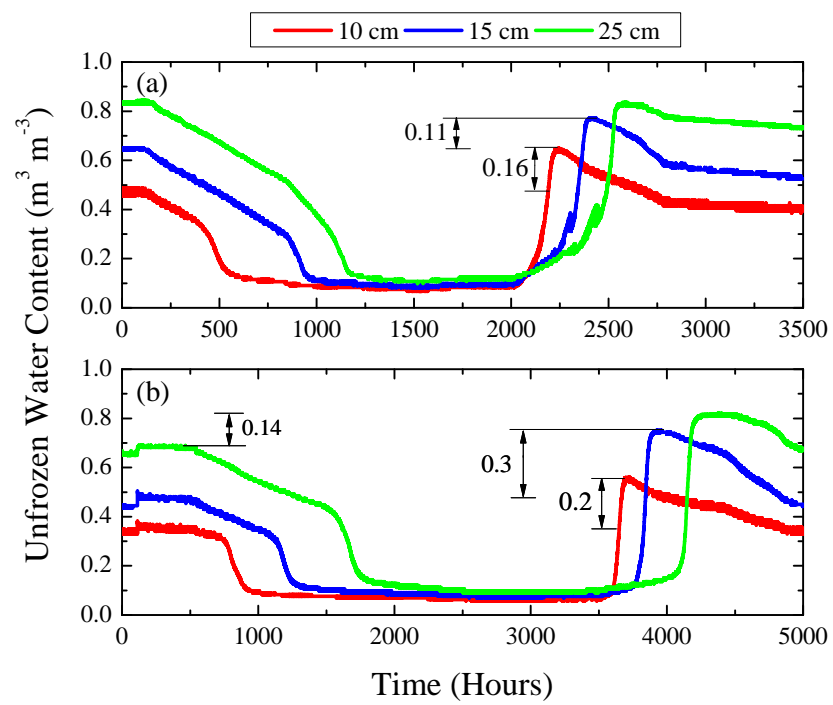

Fig. 8. Unfrozen water content time series of Mesocosm 1 for (a) run 1 and (b) run 2. Please note the different time axes for runs 1 and 2 . The difference in water contents $\left(\mathrm{m}^{3} \mathrm{~m}^{-3}\right)$ prior to freezing and after thawing is also shown. The temperature boundary conditions (air temperature in upper and lower chambers) for runs 1 and 2 are shown in Fig. 9.

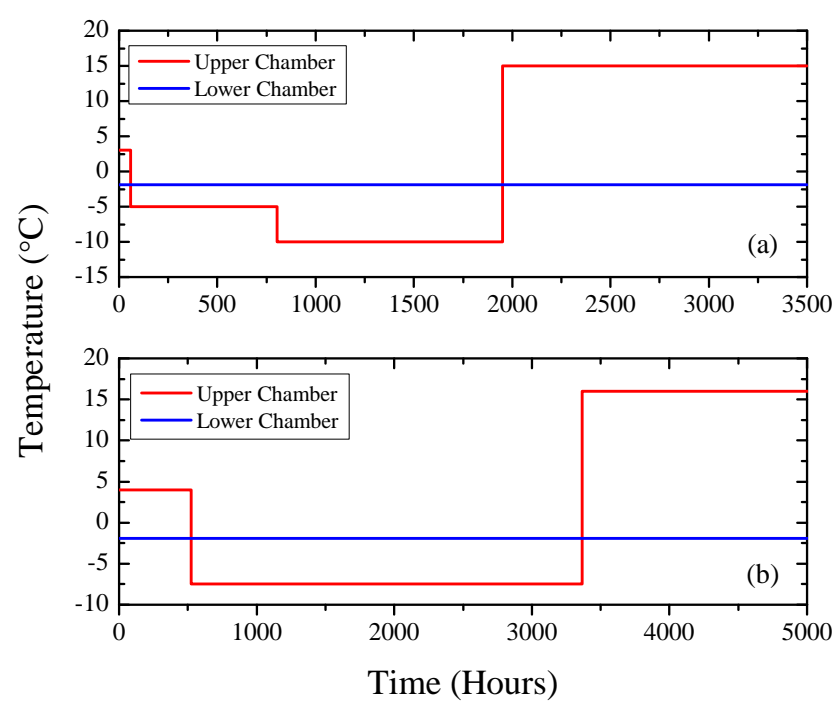

Fig. 9. Temperature boundary conditions (air temperature in upper and lower chambers) during (a) run 1 and (b) run 2. Note the differences in axis limits.

the difference in the mass balance calculation. It must be noted that the initial water content in upper $40 \mathrm{~cm}$ depth in both Mesocosms (Fig. 5) was higher than the initial water content in the field (initial moisture in Fig. 11). Also, the water table was within upper $40 \mathrm{~cm}$ depth in both Mesocosms and the air temperature at the surface was constantly at $-7.5^{\circ} \mathrm{C}$. All these conditions may have resulted into relatively larger amount of water movement towards the freezing 

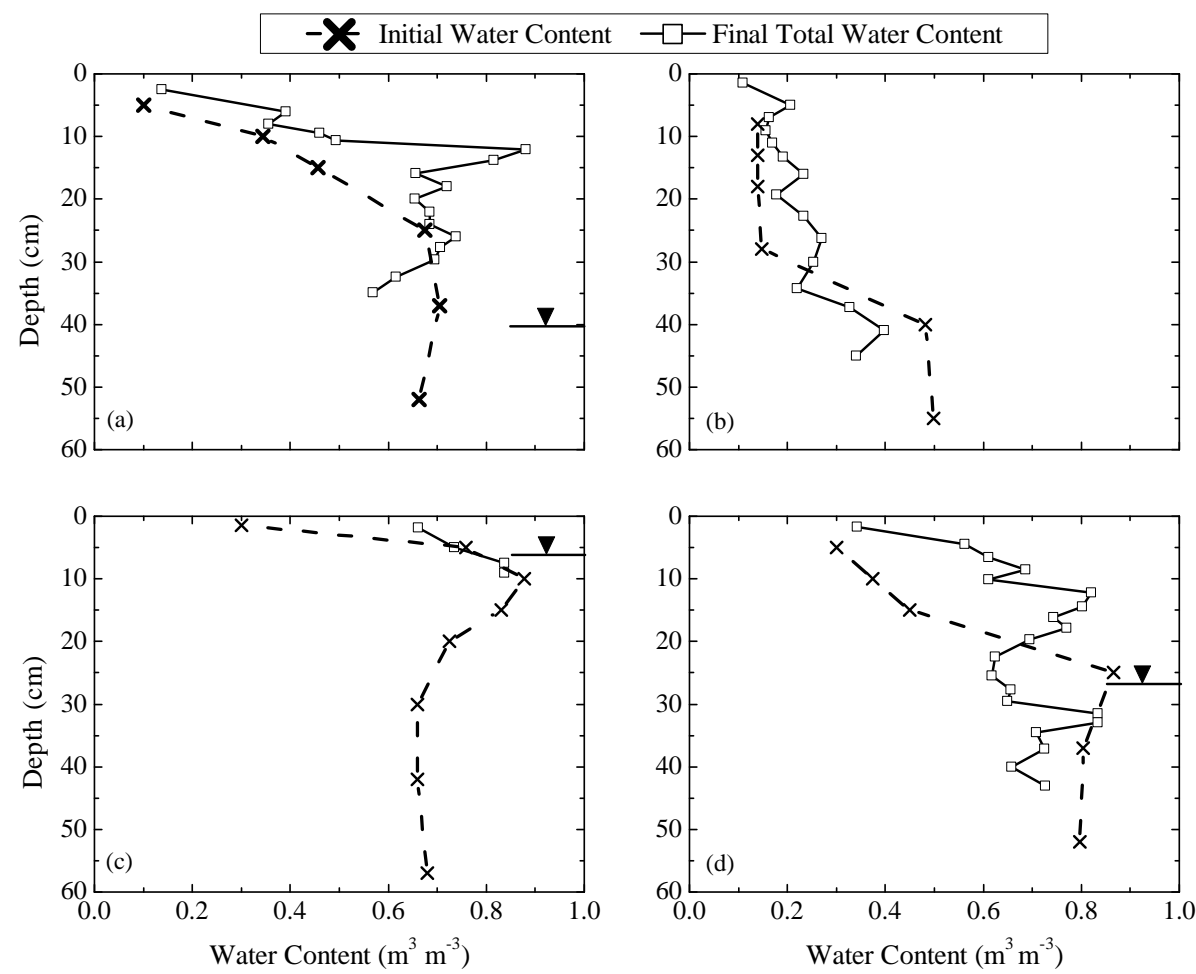

Fig. 10. Initial (liquid) and final (total) water content after $2000 \mathrm{~h}$ of freezing during the second freezing run in Mesocosms (a) 1 , (b) 2 , (c) 3 , and (d) 4. The depth to the groundwater table from top surface at the start of the freezing run is shown by free water surface symbol.

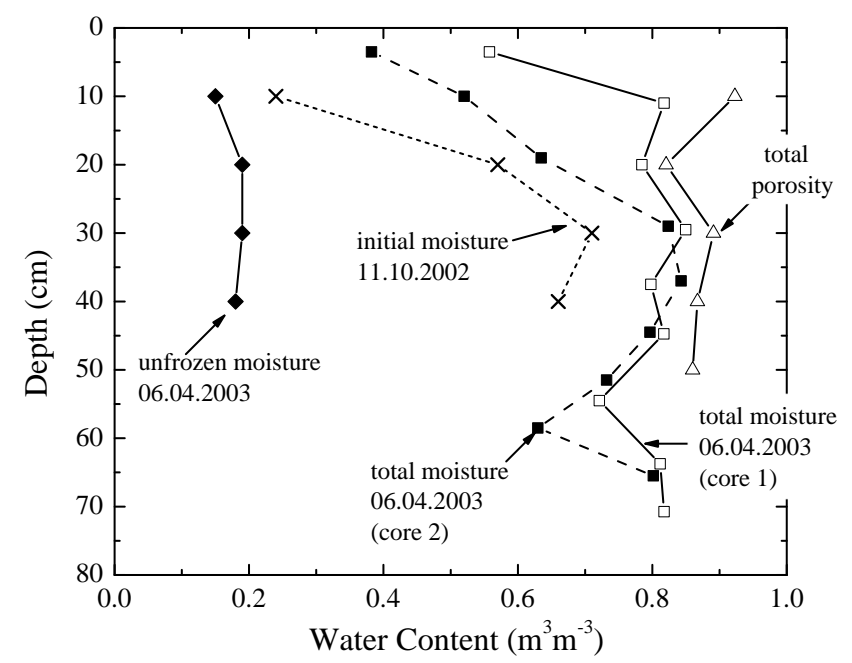

Fig. 11. Observed initial (liquid) and final water contents (liquid + ice) at Scotty Creek field site for winter of 2002-2003 (Quinton and Hayashi, 2008). The initial and unfrozen moisture content readings are from a soil pit being measured using a water content reflectometer. Two frozen cores were sampled at the end of winter season near the soil pit and total (liquid + ice) water content was determined gravimetrically. front in the Mesocosms than in the field. This is an important observation as it suggests that temperature gradients drive an upward flux of water from deeper regions of the soil into the upper $10 \mathrm{~cm}$ zone where it can be supplemented by an intermittent downward flux of snowmelt water over the winter period. This combination of freezing induced upward migration of water supplemented by an intermittent downward flux of snowmelt water over the winter period results into raising the upper surface of the frozen, saturated soil typically within about $0.1 \mathrm{~m}$ below the ground surface.

\subsection{Soil temperature and freezing front propagation}

Figure 12 shows the isothermal maps for all four Mesocosms plotted from temperature measurements during the second freezing run. Bi-directional freezing, with a relatively fast moving downward and a slower moving upward freezing front, can be observed in all four Mesocosms. The freezing front propagates faster and deeper in upper dry $\sim 35 \mathrm{~cm}$ of M2 due to minimal latent heat release. Freezing slows down considerably below this depth due to relatively high saturation and latent heat effects. Strong thermal gradients can be seen near surface in the wetter M1, M3 and M4 Mesocosms indicating presence of high amounts of water near the freezing front. In all four Mesocosms, the propagation of freezing front is controlled by competing roles of thermal diffusivity and latent heat. The slow progression of the freezing front 
(a)

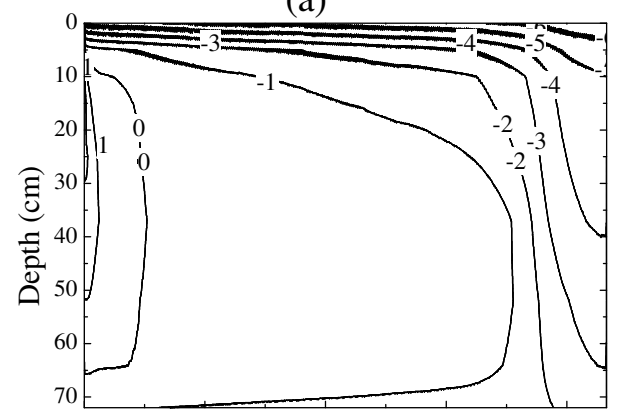

(c)

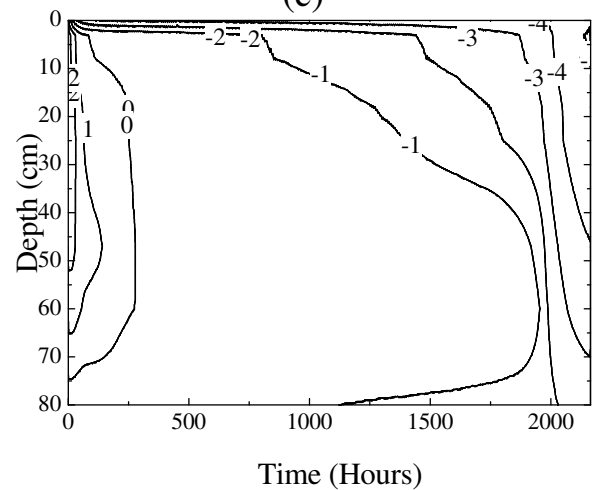

(b)

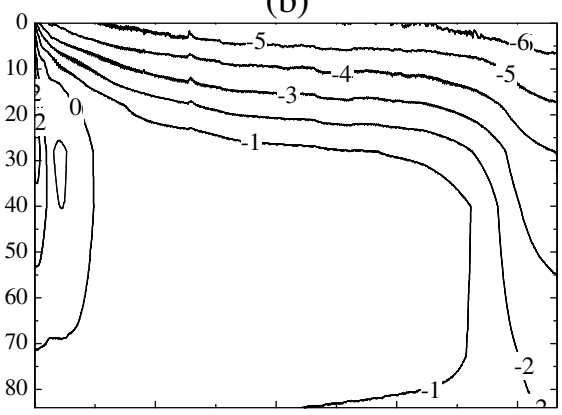

(d)

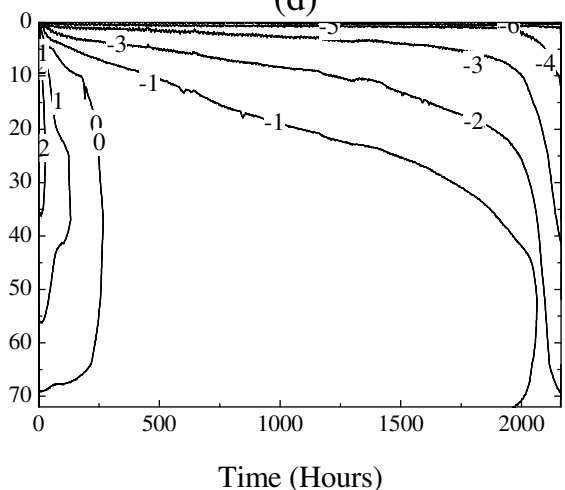

Fig. 12. Isolines of equal temperature across depth and time for (a) M1, (b) M2, (c) M3 and (d) M4.

in $\mathrm{M} 2$ below the upper $30 \mathrm{~cm}$ is due to a combination of latent heat, and low thermal conductivity owing to drier peat and higher air volume relative to M1, M3 and M4. The role of higher water content in heat balance can be seen from the difference in ground heat flux (from heat balance calculations based on Hayashi et al., 2007) for Mesocosms M2 and M3 (Fig. 13). It can be seen that the cumulative heat removed from the saturated Mesocosm M3 is higher than from the dry M2. This is because of more contribution from latent heat and higher thermal conductivity in the M3 as compared to M2. Most water in Mesocosms M1, M3 and M4 freezes around $\sim 2000 \mathrm{~h}$ after which the freezing front propagates deeper and at a higher rate. Thus, latent heat plays a significant role in keeping the soil warm, yet higher water contents result in colder horizons at depths owing to higher thermal conductivity and lower heat capacity during late freezing periods.

The results of this study are used to describe the evolution of frost table topography for a peat plateau through a simple conceptual model (Fig. 14). While the model is hypothetical, it provides a useful framework for discussion. At the onset of winter, the organic active layer resembles a variable moisture landscape made up of areas with (1) full saturation (under the topographic depression); (2) low moisture content (dry surface layer); and (3) relatively wetter unsaturated zone below the dry surface layer and under the mound. The water table more or less resembles the surface topography. When the air temperatures drop below freezing, the

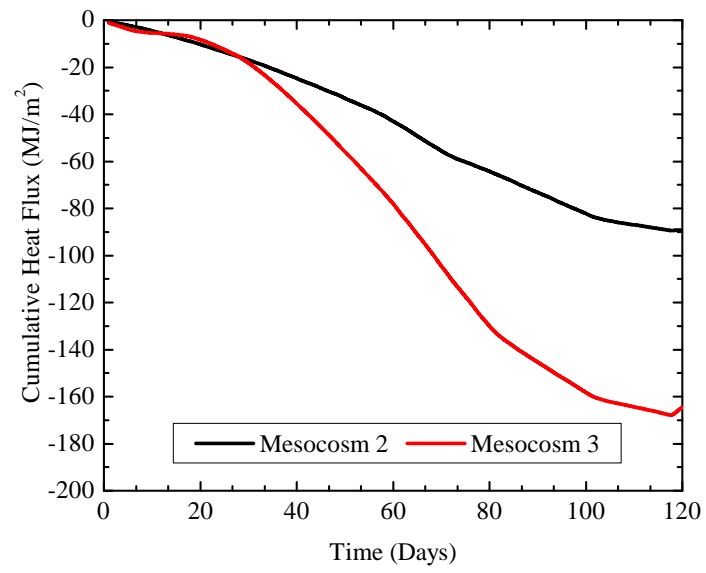

Fig. 13. Calculated cumulative ground heat flux in fully saturated M3 and dry M2.

freezing front migrates at variable rates in the different regions. The rate of migration in early winter is maximum in the dry surface layer because there is very little moisture to slow down the descent (Fig. 14b). In comparison the rate of freezing front movement is slowest under the topographic depression where peat is fully saturated. Water from the regions just above the water table moves upward in response to the pressure head gradient created between the colder and warmer regions drawing the water table downward. As the 

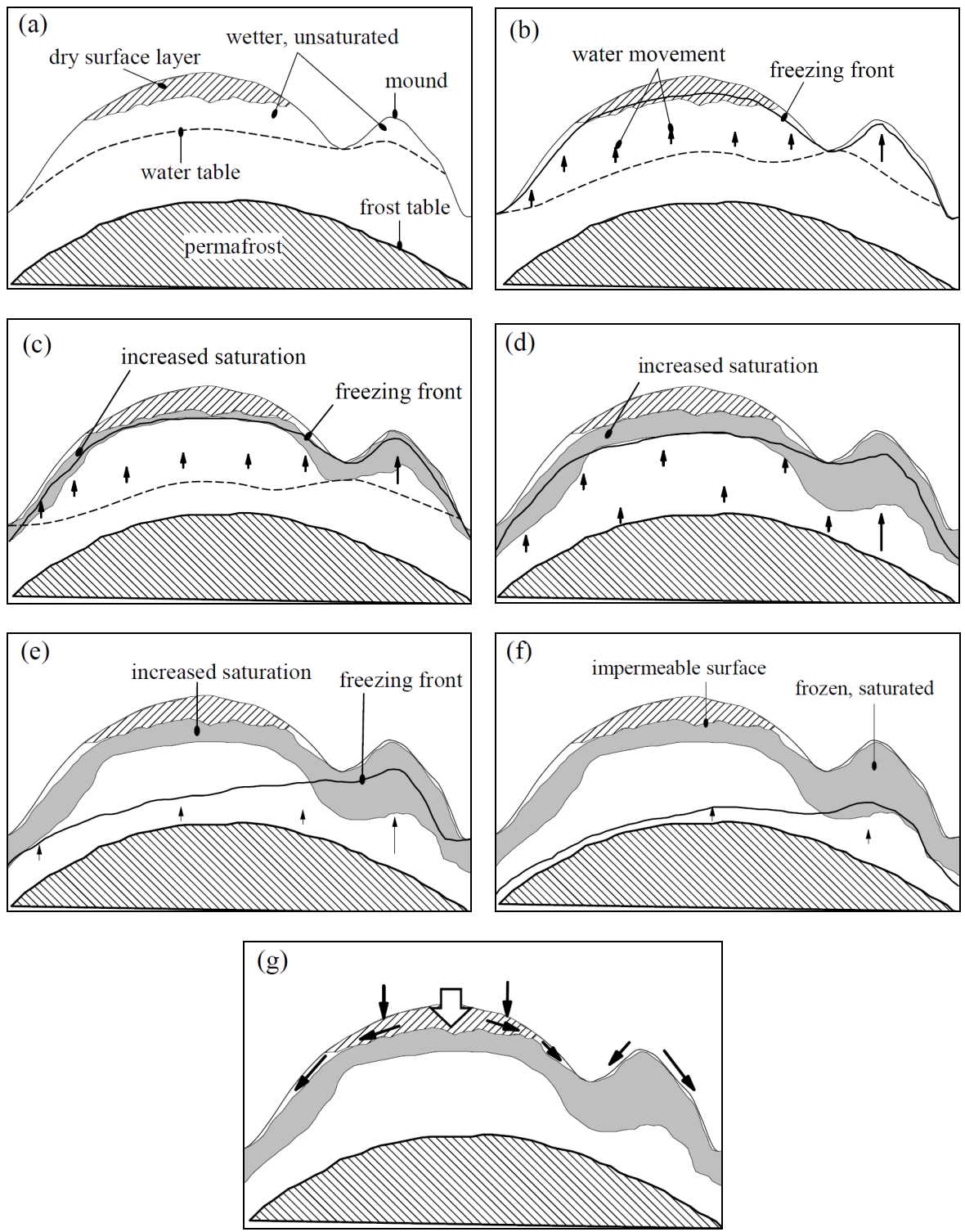

Fig. 14. Conceptual model describing freezing induced water redistribution and freezing front propagation inside an organic active layer on a peat plateau (a) onset of winter, (b) early winter, (c) early-mid winter, (d) mid winter, (e) and (f) mid-late winter, and (g) end of winter and spring runoff (large downward arrow denotes unimpeded infiltration). Variable moisture landscape made up of regions with deeper unsaturated zones plus dry surface layer (zone of lower hydraulic conductivity) and shallow water table with wetter unsaturated zone (zone of higher hydraulic conductivity) result into variable amount of freezing induced moisture movement and different rates of freezing front movement. Note: gray areas indicate regions with saturation approaching total porosity. The freezing front separates the gray areas into regions with frozen (partially or fully) and unfrozen states. Soil pores in regions above the freezing front contain ice and liquid water (frozen) and below the freezing front contain liquid water only (unfrozen). Pores of unsaturated soil (white areas) above the freezing front contain liquid water, ice and air, and below the freezing front contain liquid water and air only.

winter progresses, so does the freezing front drawing more water from regions of higher saturation creating a continuous zone of increased saturation just below it (Fig. 14c). Much more water is accumulated behind the freezing front in regions where the initial water content in unsaturated zone was relatively high (e.g., under the mound higher rate of water flow is shown by longer arrow). This occurs because of the higher hydraulic conductivity of the wetter unsaturated zones as compared to the drier ones. In comparison, the initially dry surface layer remains on lower side of saturation because the low hydraulic conductivity in this layer slows down the upward movement of water beyond its interface with the wetter unsaturated zone underneath. By mid-winter (Fig. 14d), there is no longer a saturated unfrozen zone on the entire peat 
plateau. The entire plateau is unsaturated because of freezing induced water redistribution or partial freezing of soil water. The soil moisture migration towards freezing front continues from areas where there is still substantial liquid water. As the water accumulating behind the freezing front freezes, it also retards the movement of the freezing front (Fig. 14c and d). The rate of descent still is slowest below the topographic depression and the mound where the zone of increased saturation is at its maximum thickness behind the freezing front. By mid to late winter (Fig. 14e and f), most of the water behind the freezing front is frozen, except under the topographic depression and the mound. Elsewhere on the peat plateau, the downward freezing front movement accelerates. By this time, freezing induced water movement has slowed down considerably except near the depression where the larger effects of temperature on soil matric potential (due to higher ice contents) and initially higher hydraulic conductivity, result in a comparatively higher rate of upward water redistribution. As most water freezes behind the freezing front, the front migrates much more rapidly owing to increased thermal conductivity and lower release of latent heat. By the end of winter most water redistribution ceases and the entire soil profile is now below freezing temperatures. The significant water movement upwards in early to mid, latemid winter periods results in a continuous saturated frozen layer near surface of varying thickness. The thickness is minimum below the dry surface layer and maximum below the topographic depression and the mound. This saturated frozen layer creates a near impermeable frost table near surface with variable thickness of unsaturated zone above it. As spring arrives and snow melts, runoff takes place in different modes in different regions of the peat plateaus. There is unimpeded infiltration into the dry surface layer with lowest ice content. The infiltrating water runs off down-slope along the topography of the frost table through the subsurface. Near the topographic depression and the mound, where the impermeable surface is flush with ground surface, most snowmelt runoff takes place as overland flow along the topographic slopes.

\section{Conclusions and implications}

Four peat Mesocosms with different initial moisture contents were subjected to freezing to study the impact of soil water content on soil freezing characteristics, freezing induced soil water redistribution, and frost penetration.

There appears to be very little effect of initial soil moisture on soil freezing characteristics of peat. This implies that liquid water content in frozen peat has a fixed value for each temperature at which the liquid and ice phase are in equilibrium, regardless of the amount of ice present. A single freezing curve can be derived, regardless of initial soil moisture. This simplifies the temperature-liquid water content parameterization required for numerical studies. Initial moisture profiles seem to control the amount of water moving upwards by influencing the hydraulic conductivities in variably saturated media. Substantial water redistribution appears to have taken place within the active layer during its freezing. This suggests that under favorable conditions the water moving from deeper depths under temperature gradients, with "complementary" contribution from preceding over-winter melt events, could be sufficient to raise the upper surface of frozen saturated soil within upper $10 \mathrm{~cm}$ zone. It is also likely that water from slowly freezing bogs moves up-slope resulting into fully saturated active layer on permafrost plateaus at the end of winter season. Diffusion under moisture gradients and effects of temperature on soil matric potential, at least in the initial period, appear to drive such movement towards freezing front. Initial water content in the surface layer $(\sim 10 \mathrm{~cm})$ appears to control the amount of ice and location of the zone where maximum ice is formed near the surface. It appears that if there is a relatively thick dry layer, then water moving towards the freezing front from below is accumulated relatively at a deeper depth as compared to if the surface layer was moist. Also, the ice content in a dry surface layer would be much lower than a relatively wetter surface layer. This has implications in the timing and mode of runoff during the initial thaw period because an initially dry surface layer would result into unimpeded higher infiltration.

The freezing front movement in the four Mesocosms with different initial moisture content shows that it's movement in freezing peat is controlled by a combination of latent heat and thermal properties of the peat-air-water-ice system. Latent heat governs the frost penetration for a long time during freezing because of high water contents in peat. Once water in peat is frozen, higher thermal conductivity and lowered heat capacity of frozen peat-ice system helps in faster movement of the freezing front. Climate change scenarios predict shorter periods of snow cover in northern latitudes (Serreze et al., 2000; IPCC, 2007). This will increase the rate of freezing of peat pore water. If the peat contains substantial water at the onset of winter, then this might lead into deeper frost depths. Mean annual air temperature and rainfall in the northern hemisphere are also predicted to increase (Serreze et al., 2000; IPCC, 2007). A system with competing dynamics of frost penetration due to longer ground exposure to winter air temperatures and overall higher annual mean air temperature forcing deeper permafrost appears to be a possible scenario.

This study demonstrates that soil moisture profiles at the onset of winter play an important role in modulating the hydraulic and thermal properties of peat and therefore affecting the freezing induced water redistribution and freezing front propagation during the freezing of active layer. For example, the results of this study are in agreement with the modeling study of Jorgenson et al. (2010) in which the modeled temperatures for permafrost overlain by dry organic mats was found to be much colder than for wet overlying mats. The results of this study will help in understanding, and ultimately forecasting, the seasonal freeze-thaw hydrologic response of 
wetland-dominated terrain underlain by discontinuous permafrost. Further research through numerical modeling and laboratory work involving experimental design similar to that of this study is required to understand the exact mechanisms of water flow in freezing peat, and the impacts of the competing dynamics driving the water and heat movement in frozen peat.

Acknowledgements. We wish to acknowledge the financial support of the Natural Science and Engineering Research Council (NSERC) and BioChambers Inc. (MB, Canada) through a NSERC-CRD award, NSERC Strategic Projects grant, and the Canadian Foundation for Climate and Atmospheric Sciences (CFCAS) through an IP3 Research Network grant. We also thank Andrea Kenward, Trevor Meyers and Pete Whittington for their assistance in the field, and acknowledge the help of Frank Van Sas, Brian Dalrymple, Jonathan Jacobs, Jeremy Bird and Jalpa Pal in setting up the Mesocosm experiment. We acknowledge the Aurora Research Institute for their assistance in obtaining a research license, and thank the Denedeh Resources Committee, Deh Cho First Nation, Fort Simpson Métis Local \#52, Liidlii Kue First Nation, Jean-Marie First Nation and the Village of Fort Simpson for their support of this project.

Edited by: E. Zehe

\section{References}

Carey, S. K. and Woo, M. K.: Freezing of subarctic hillslopes, Wolf Creek basin, Yukon, Canada, Arct. Antarct. Alpine Res., 37, 110, 2005.

Dash, J. G., Fu., H., and Wettlaufer, J. S.: The premelting of ice and its environmental consequences, Rep. Prog. Phys., 58, 116-167, 1995.

de Vries, D. A.: Thermal Properties of Soils, in: Physics of Plant Environment, edited by: van Wijk, W. R., North-Holland Pub. Co., 210-235, 1963.

Dirksen, C.: Water Movement and Frost Heaving in Unsaturated Soil without an External Source of Water, Ph.D. thesis, Cornell University, United States - New York, 152 pp., 1964.

Dirksen, C. and Miller, R. D.: Closed-System Freezing of Unsaturated Soil, Soil Sci. Soc. Am. Pro., 30, 168-173, 1966.

Gamayunov, N. I., Stotland, D. M., Agafonova, O. N., and Tovbin, I. B.: Investigation of heat and mass transport during freezing in peat soils, Soviet Soil Sci., 22, 88-97, 1990.

Gergely, M.: Dynamics of a salty permafrost, M.Sc. thesis, University of Heidelberg, Germany, 2007.

Glenn, M. S. and Woo, M.-K.: Spring and summer hydrology of a valley-bottom wetland, Ellesmere Island, Northwest Territories, Canada, Wetlands, 17, 321-329, 1987.

Gray, D. M., Norum, D. I., and Wigham, J. M.: Infiltration and physics of flow of water through porous media, in: Handbook on the Principles of Hydrology, edited by: Gray, D. M., Canadian National Committee of the International Hydrological Decade, Ottawa, 1970.

Gray, D. M., Landine, P. G., and Granger, R. J.: Simulating Infiltration into Frozen Prairie Soils in Streamflow Models, Can. J. Earth Sci., 22, 464-472, 1985.
Gray, D. M., Toth, B., Pomeroy, J. W., Zhao, L., and Granger, R. J.: Estimating areal snowmelt infiltration into frozen soils, Hydrol. Process., 15, 3095-3111, 2001.

Guymon, G. L., Berg, R. L., and Hromadka, T. V.: Mathematical Model of Frost Heave and Thaw Settlement in Pavements, US Army Corps Cold Regions Research \& Engineering Laboratory, 130 pp., 1993.

Hansson, K., Simunek, J., Mizoguchi, M., Lundin, L. C., and van Genuchten, M. T.: Water flow and heat transport in frozen soil: Numerical solution and freeze-thaw applications, Vadose Zone J., 3, 693-704, 2004.

Hayashi, M., Goeller, N., Quinton, W. L., and Wright, N.: A simple heat-conduction method for simulating the frost-table depth in hydrological models, Hydrol. Process., 21, 2610-2622, doi:10.1002/hyp.6792, 2007.

Hoekstra, P.: Moisture Movement in Soils Under Temperature Gradients with Cold-Side Temperature Below Freezing, Water Resour. Res., 2, 241-250, 1966.

IPCC, 2007: Climate Change 2007: The Physical Science Basis. Contribution of Working Group I to the Fourth Assessment Report of the Intergovernmental Panel on Climate Change, edited by: Solomon, S., Qin, D., Manning, M., Chen, Z., Marquis, M., Averyt, K. B., Tignor, M., and Miller, H. L., Cambridge University Press, Cambridge, UK and New York, NY, USA, 2007.

Jame, Y.: Heat and Mass Transfer in Freezing Unsaturated Soil, Ph.D. thesis, The University of Saskatchewan, Canada, 212 pp., 1978.

Jame, Y. W. and Norum, D. I.: Heat and Mass-Transfer in a Freezing Unsaturated Porous-Medium, Water Resour. Res., 16, 811-819, 1980.

Jorgenson, M. T., Romanovsky, V., Harden, J., Shur, Y., O’Donnell, J., Schuur, E. A. G., Kanevskiy, M., and Marchenko S.: Resilience and vulnerability of permafrost to climate change, Can. J. Forest Res., 40, 1219-1236, 2010.

Kane, D. L. And Stein, J.: Water movement into seasonally frozen soils, Water Resour. Res., 19, 1547-1557, 1983.

Low, P. F., Anderson, D. M., and Hoekstra, P.: Some Thermodynamic Relationships for Soils at Or Below Freezing Point, 1. Freezing Point Depression and Heat Capacity, Water Resour. Res., 4, 379-394, 1968.

Mizoguchi, M.: Water, heat and salt transport in freezing soil, Ph. D thesis, University of Tokyo, Tokyo, 1990.

Nagare, R. M.: Coupled Heat and Water Transport in Frozen Organic Soils, Ph.D. thesis, The University of Western Ontario, London, Canada, ON, 191 pp., 2011.

Nagare, R. M., Schincariol, R. A., Quinton, W. L., and Hayashi, M.: Laboratory calibration of time domain reflectometry to determine moisture content in undisturbed peat samples, Eur. J. Soil Sci., 62, 505-515, 2011.

Pepin, S., Livingston, N. J., and Hook, W. R.: Temperaturedependent errors in time domain reflectometry determinations of soil water, Soil Sci. Soc. Am. Pro., 59, 38-43, 1995.

Philip, J. R. and de Vries, D. A.: Moisture movement in porous materials under temperature gradient, Trans. Am. Geophys. Union, 38, 222-232, 1957.

Quinton, W. L. and Hayashi, M.: The flow and storage of water in the wetland-dominated central Mackenzie river basin: Recent advances and future directions, in: Prediction in ungauged basins: Approaches for Canada's cold regions, edited by: Spence, C., 
Pomeroy, J. W., and Pietroniro, A., Canadian Water Resources Association, 45-66, 2005.

Quinton, W. L. and Hayashi, M.: Recent Advances Toward Physically-based Runoff Modeling of the Wetland-dominated Central Mackenzie River Basin, in: Cold Region Atmospheric and Hydrologic Studies, The Mackenzie GEWEX Experience: Volume 2: Hydrologic Processes, edited by: Woo, M., Springer, Berlin, 257-279, 2008.

Quinton, W. L., Gray, D. M., and Marsh, P.: Subsurface drainage from hummock covered hillslopes in the Arctic Tundra, J. Hydrol., 237, 113-125, 2000.

Quinton, W. L., Shirazi, T., Carey, S. K., and Pomeroy, J. W.: Soil water storage and active-layer development in a sub-alpine tundra hillslope, southern YukonTerritory, Canada, Permafrost Periglac. Process., 16, 369-382, 10.1002/ppp.543, 2005.

Quinton, W. L., Hayashi, M., and Carey, S. K.: Peat hydraulic conductivity in cold regions and its relation to pore size and geometry, Hydrol. Process., 22, 2829-2837, doi:10.1002/hyp.7027, 2008.

Quinton, W. L., Elliot, T., Price, J. S., Rezanezhad, F., and Heck, R.: Measuring physical and hydraulic properties of peat from X-ray tomography, Geoderma, 153, 269-277, doi:10.1016/j.geoderma.2009.08.010, 2009.

Rezanezhad, F., Quinton, W. L., Price, J. S., Elrick, D., Elliot, T. R., and Heck, R. J.: Examining the effect of pore size distribution and shape on flow through unsaturated peat using computed tomography, Hydrol. Earth Syst. Sci., 13, 1993-2002, doi:10.5194/hess-13-1993-2009, 2009.

Schlotzhauer, S. M. and Price, J. S.: Soil water flow dynamics in a managed cutover peat field, Quebec: Field and laboratory investigations, Water Resour. Res., 35, 3675-3683, 1999.

Serreze, M. C., Walsh, J. E., Chapin, F. S., Osterkamp, T., Dyurgerov, M., Romanovsky, V., Oechel, W. C., Morison, J., Zhang, T., and Barry, R. G.: Observational evidence of recent change in the northern high-latitude environment, Climatic Change, 46, 159-207, 2000.
Smerdon, B. D. and Mendoza, C. A.: Hysteretic freezing characteristics of riparian peatlands in the Western Boreal Forest of Canada, Hydrol. Process., 24, 1027-1038, doi:10.1002/hyp.7544, 2010.

Smith, S. L., Burgess, M. M., Riseborough, D., Coultish, T., and Chartrand, J.: Digital summary database of permafrost and thermal conditions - Norman Wells pipeline study sites, GSC Open File 4635, 2004.

Stahli, M. and Stadler, D.: Measurement of water and solute dynamics in freezing soil columns with time domain reflectometry, J. Hydrol., 195, 352-369, 1997.

van Genuchten, M. T.: A closed-form equation for predicting the hydraulic conductivity of unsaturated soils, Soil Sci. Soc. Am. J., 44, 892-898, 1980.

Watanabe, K. and Wake, T.: Measurement of unfrozen water content and relative permittivity of frozen unsaturated soil using NMR and TDR, Cold Reg. Sci. Tech., 59, 34-41, 2009.

Williams, P. J.: Properties and behavior of freezing soils, Norwegian Geotechnical Institute, Research paper \# 359, 128 pp., 1967.

Wohlfarth, C.: Permittivity (Dielectric Constant) of Liquids, in: CRC Handbook of Chemistry and Physics, 91, edited by: Haynes, W. M., Taylor and Francis Group, LLC, 6-186-6-207, 2010.

Woo, M.-K.: Permafrost hydrology in North America, Atmos. Ocean, 24, 201-234, 1986.

Wright, N., Hayashi, M., and Quinton, W. L.: Spatial and temporal variations in active layer thawing and their implication on runoff generation in peat-covered permafrost terrain, Water Resour.Res., 45, W05414, doi:10.1029/2008WR006880, 2009.

Zhang, Y., Carey, S. K., Quinton, W. L., Janowicz, J. R., Pomeroy, J. W., and Flerchinger, G. N.: Comparison of algorithms and parameterisations for infiltration into organic-covered permafrost soils, Hydrol. Earth Syst. Sci., 14, 729-750, doi:10.5194/hess14-729-2010, 2010. 